ARTICLE

\title{
Longitudinal perspectives of faculty and students on benefits and barriers to transdisciplinary graduate education: program assessment and institutional recommendations
}

\author{
Anna-Sigrid Keck ${ }^{1,2}$, Stephanie Sloane 3,4 , Janet M. Liechty 1,2,5,6, Megan S. Paceley 5,7 , Sharon M. Donovan ${ }^{1,2,3}$, \\ Kelly K. Bost $2,3,4$, Brent A. McBride $2,3,4$ \& Barbara H. Fiese $2,3,4$
}

\begin{abstract}
Addressing complex societal problems, such as childhood obesity, requires transdisciplinary (TD) approaches to reach effective solutions. However, TD doctoral training programs in academic settings are still relatively new, and little is known about the benefits and barriers of participation. This study sought to longitudinally assess benefits and barriers of a TD approach to doctoral education from the perspectives of students working towards a joint PhD/MPH degree and their faculty advisors. Results show that benefits across 5-years included greater collaboration and networking, enhanced guidance and support, broadened ways of thinking, and expanded opportunities. Barriers included time demands, complicated logistics, and tension between depth versus breadth of knowledge. Similarities and differences among students and faculty are discussed. Findings provide resources for both faculty and students considering involvement with TD doctoral education, as well as for institutions and academic programs seeking to promote TD training and team science.
\end{abstract}

\footnotetext{
${ }^{1}$ Division of Nutritional Sciences, University of Illinois at Urbana-Champaign, 905 S Goodwin Ave, Bevier Hall, Champaign, IL 61801, USA. ${ }^{2}$ Illinois Transdisciplinary Obesity Prevention Program (I-TOPP), Urbana, IL, USA. ${ }^{3}$ Family Resiliency Center, University of Illinois at Urbana-Champaign, Champaign, IL, USA. ${ }^{4}$ Department of Human Development and Family Studies, University of Illinois at Urbana-Champaign, Champaign, IL, USA. ${ }^{5}$ School of Social Work, University of Illinois at Urbana-Champaign, Champaign, IL, USA. ${ }^{6}$ College of Medicine, University of Illinois at Urbana, Champaign, IL, USA. ${ }^{7}$ School of Social Welfare, University of Kansas, Lawrence, KS 66045, USA. Correspondence and requests for materials should be addressed to

A.-S.K. (email: akeck@illinois.edu)
} 


\section{Introduction}

ddressing complex societal problems demands coordinated effort from many sectors, stakeholders, and disciplines (World Health Organization, 2016). Increasingly, the concept of convergence between life sciences, engineering, social sciences, and other fields is viewed as a key to unlocking innovative solutions to complex global problems such as childhood obesity (National Research Council (NRC), 2014). Higher education plays a critical role in teaching and cultivating transdisciplinary (TD) team science, which we define in this paper as approaches that vertically integrate theories and bodies of knowledge across diverse disciplines and horizontally integrate approaches from stakeholders at multiple levels of the social ecology from individuals and families to communities to policy makers, in order to generate novel ways to address grand challenges (Bernstein, 2015; Hirsch et al., 2008; Jacob, 2015; Neuhauser et al., 2007; Neuhauser and Pohl, 2015; Stokols, 2006, 2013). However, the institutional and programmatic infrastructure and practical pedagogical strategies to support training in TD science are still emerging (Jacob, 2015; NRC, 2014; Neuhauser et al., 2007; Willetts and Mitchell, 2016).

TD research promotes integration across intrapersonal, interpersonal, organizational, community, and societal levels on social problems (Abrams, 2006; Stokols et al., 2013) such that traditional disciplinary boundaries become blurred (Townsend et al., 2015). Utilizing teams of researchers from a variety of fields is critical, as one discipline alone cannot provide all the answers. Thus, educational programs that teach TD approaches go beyond multi-disciplinary and interdisciplinary in order to foster syntheses across academic disciplines while seeking input from nonacademic stakeholders (such as practitioners and policy makers) in order to solve real societal problems (Wall and Shankar, 2008). Such efforts are designed to yield new ways of analyzing and solving problems from multiple stakeholder perspectives and at various levels of inquiry (Bernstein, 2015; Harrison et al., 2011; Stokols et al., 2013).

Additional programs and pedagogies in higher education are needed to promote TD learning. Furthermore, these programs must be critically examined and evaluated, so that we can move toward using evidence-based TD education (Shandas and Brown, 2016). There is growing attention to evaluating TD training. For example, recently Willetts and Mitchell (2016) have proposed a framework for evaluating the dissertation examination process of TD doctoral research, including quality criteria. The potential benefits and barriers of TD training may be similar to those previously identified in interdisciplinary doctoral programs, which in some instances have been defined similarly to TD programs (Graybill et al., 2006; Bosque-Pérez et al., 2016). Graybill and colleagues (2006) found that doctoral students in an interdisciplinary program struggled with academic identity, what to prioritize, and academic productivity. Other studies have identified TD training challenges and TD approaches among faculty and scientists such as learning to speak the language of multiple disciplines, navigating between disciplines, managing criticism from those working in single disciplines, and concerns about TD approaches lacking focus (Nash, 2008; Neuhauser, 2007; Stokols et al., 2008a; Vanasupa et al., 2012). Potential benefits of TD approaches also warrant exploration. One study that evaluated teams of established TD scientists at large research centers, reported a benefit of increased scientific productivity compared to disciplinary approaches (Cooper et al., 2013; Hall et al., 2008, 2012). However, little is known about the benefits and barriers over time of participating in emerging TD doctoral education programs as perceived by both faculty and students.

The formation of this TD training program was a result of the increased urgency to address the complex global public health crisis of childhood obesity (Harrison et al., 2011; Nishtar et al., 2016). In 2007, a campus collaboration began forming, and members developed a shared ecological model of childhood obesity, proposed a research project together, and obtained state funding to conduct a prospective panel study and sub-projects. Out of this collaboration, the vision for a TD doctoral training program emerged and a leader stepped forward. A team of thirteen faculty from nine disciplines were brought together to develop a TD training program to equip doctoral students with the cross-disciplinary tools to address childhood obesity prevention and public health. This group sought and secured funding for this innovative opportunity through the USDA in 2011. The purpose of this study was to explore the benefits and barriers to being involved in a TD doctoral training program from the perspectives of faculty and their students. This study also aimed to generate new insights to inform and guide institutions seeking to facilitate more TD education, faculty making decisions about investing time in TD endeavors, and students considering TD doctoral training.

\section{Methods}

This study is part of a larger comprehensive evaluation of a federally funded TD doctoral program. To answer the research questions of this exploratory longitudinal study, data from focus groups were utilized to identify benefits and barriers of a TD approach from the perspectives of faculty and their students during the first five years of the TD program (2011-2015).

TD program description. This federally funded TD training program, started in 2011, is a joint $\mathrm{PhD}$ and Masters of Public Health (MPH) degree program that integrates education, research, and practice. A total of 13 students have been enrolled in this program (four in 2011, four in 2012, and five in 2013). It includes MPH coursework, capstone project, and practicum (or prior MPH degree) and a full disciplinary doctoral degree. In addition, students take courses in TD approaches to childhood obesity prevention, and conduct TD research projects. The program provides opportunities for broad cross-disciplinary interactions between faculty and students with leading international researchers, community stakeholders, and practitioners through a visiting faculty program, lecture series, capstone project, practicum, and biennial symposium (http://i-topp.fshn.illinois. edu/). The practicum and capstone project give students critical exposure to transdisciplinary settings of practice where complex challenges are revealed (McDaniels and Skogsberg, 2017), and this applied experience then shapes their TD research questions and collaborations. Students are provided with annual travel funds to present at conferences, and opportunities to apply for seed grants to support their dissertation research. A program coordinator supports the daily operations, collects and analyzes program evaluation data, and arranges teambuilding and professional development opportunities. The structure of this TD program allows students to learn the terminology and basic research approaches of other disciplines, while developing depth in their primary discipline. Thus, they develop their professional identity in a context informed and broadened by exposure to cross-disciplinary models, theories, and methods that promote a TD mindset. Students are mentored by a primary and secondary advisor from two disciplines, in consultation with other faculty and visiting scholars. Students meet with their Advisory Committees (faculty from at least three disciplines) at least yearly to select courses, develop their TD research, and set annual research and professional development goals reflected in an annual individual development plan that is also reviewed and approved by the I-TOPP Annual Student Review Committee.

Participants. Participants included faculty advisors (all 13 at baseline and 8 of 13 at five years) and their doctoral students (13 at baseline and 11 at five years) who were part of the TD program; students were from five and faculty from nine disciplines (i.e., Food Science, Nutrition, Human Development and Family Studies, Kinesiology, Community Health, Agricultural and Consumer Economics, Animal Sciences, Social Work, and Medicine). 
Faculty participated in one of three focus groups at two time points (fall 2011 and fall 2015). Each faculty focus group consisted of 2-5 participants and the same combination of faculty was maintained in each focus group at both time points. Eight faculty had less than four years of prior TD experience. At baseline, faculty had been employed $13.7 \pm 7.8$ years at $1.4 \pm 0.6$ academic institutions; eight were female (62\%), three were assistant professors (23\%), five were associate professors (38\%), and five were full professors (38\%). One faculty left and one joined the program; all 13 faculty were invited to participate with the same focus group at each time point. At five years, nine were female (69\%), one was assistant professor $(8 \%)$, three were associate professors (23\%), and nine were full professors (69\%). They self-identified as non-Hispanic African-American (1), non-Hispanic Asian (1), Hispanic White (1), and non-Hispanic White (10).

Students participated in one of three focus groups with their academic cohort upon joining the program (fall 2011, 2012, or 2013) and again in fall 2015. Each focus group consisted of 3 to 5 students, as they participated in the same cohort group for both time points. Since the second time point was five years into the training program, students in cohort $1(n=3)$ were in their fifth year of training, cohort 2 students $(n=3)$ were in their fourth year of training and cohort 3 students $(n=5)$ were in their third year of training. At baseline, students were $25.1 \pm 3.3$ years of age and 11 were female (85\%). Students self-identified as Hispanic multiracial (3), Hispanic White (1), non-Hispanic Asian (3), and non-Hispanic White (6). Students had completed $1.2 \pm 1.8$ years of graduate school at enrollment. At five years (fall 2015) two students had exited the program, so 11 students participated in the follow-up focus groups. The two students who left the program did so before the second year; one was more inclined to a mono-disciplinary approach and the other had not made satisfactory progress.

Focus groups. A focus group design was selected to identify the broadest possible understanding of perspectives and opinions at a group level rather than individual level, and it is a commonly used method in program evaluation to elicit the widest range of experiences (Hesse-Biber and Leavy, 2011). Furthermore, no standardized measures of benefits and barriers to TD education were available. Focus groups are used to measure a program's success, strengths, and weaknesses and to give a qualitative view of what is and is not working (Carey, 1994; Hesse-Biber and Leavy, 2011; Morgan, 1996; Morgan and Krueger, 1993). Focus groups yield data via a dynamic interactive process among individuals to assess "group effect" (Carey, 1994; Hesse-Biber and Leavy, 2011; Morgan, 1996; Morgan and Krueger, 1993). The group effect is greater than the sum total of individual interviews because participants can question and explain their answers to each other and this interaction indicates how similar or dissimilar each participant's experiences are (Morgan, 1996).

The focus group questions were developed by the TD assessment committee. The protocol was approved by the University's Institutional Review Board and informed consent was obtained prior to participation. The analysis for this study was based on responses to several open-ended questions from the larger protocol (e.g., Compared to a traditional PhD program, what do you think are the benefits [barriers] to students and to faculty of participating in the program?). Focus groups of five or fewer participants were scheduled separately for faculty and students. Three focus groups were conducted among faculty, and three among students at baseline (cohort 1 in fall 2011, cohort 2 in fall 2012, and cohort 3 in fall 2013) and after five years into the program; six focus groups at each time point. The same people were invited to participate in each focus group at each time point to ensure continuity within the groups. Focus groups were conducted by a trained, experienced external facilitator and were audio recorded and transcribed for analysis to enhance rigor and lower risk of error (Krueger and Casey, 2001).

Analysis plan. Transcripts were analyzed by the research team using a semantic approach to thematic analysis (Braun and Clarke, 2006) to identify benefit and barrier themes. Consistent with a realist epistemology, the semantic approach identifies explicit or surface meanings of the data (Braun and Clarke, 2006), summarizes them, and interprets their meaning, rather than examining the underlying constructs of the data. Data were analyzed using Dedoose (Version 7.0.23, Dedoose 2016).

We followed steps consistent with thematic analysis (Braun and Clarke, 2006). First, the research team read the focus group transcripts. The team then re-read the transcripts together and used discussion and consensus to identify codes. After agreement was reached about the preliminary coding structure, two members of the team coded the remaining sections of the transcripts, using this coding structure while allowing new codes to emerge. When coding was completed, the primary analysts searched for themes within the codes. The individual codes were sorted into similar categories and themes were created to conceptually organize the coded data. The analysts kept memos to define and describe the themes in more detail to ensure coding consistency. Themes were reviewed, named, and transcripts were re-read to ensure codes were not missed. In the final stages, key concepts were extracted from quotes to describe themes, and overarching meta-themes were identified (Ryan and Bernard, 2003). All codes and themes were reviewed by the team to ensure agreement (Lincoln and Guba, 1985).

Below are two examples to illustrate the semantic approach to thematic analysis.

\section{Theme: broadens ways of thinking/doing/answering}

Quote from faculty at five years: "Well, I think that the lecture series, the invited speaker series has been really, really good. I think it has exposed both faculty and students to a wide variety of really high profile people. It's been really stimulating."

Quote from students at five years: "I think it's created a lot of opportunities for us to work in different ways. I know that I'm very stubborn, and probably would still do the kind of dissertation project that I wanted, but I know that I have a justification for wanting to bring things from outside of our field."

\section{Theme: increases opportunities}

Quote from faculty at five years: "I think the fact that there is certain funding allocated for the professional development of the students is very important. I think, also, the fact that as they work toward their degree, they have an option to participate in the Seed Grant Program. So, they're getting an opportunity to write these smaller grants, which will be important, especially if they're going into academia... and they're also getting some experience articulating their ideas in a way that's going to be important in the long term."

Quote from students at five years: "We have the opportunity to explore collaborating themes, using different styles, and apply them in our work. [ITOPP] gives you that opportunity to be flexible and allocate your interests to the things that are priorities to you"

Themes discussed in this paper were mentioned in two or more of the faculty or two or more of the student focus groups, as aligned with a data reduction approach for qualitative data (Namey et al., 2008). This was important since the three student cohorts had varying training times of 3-5 years in the program. Finally, we conducted a member check (Lincoln and Guba, 1985); tables and figures were shared with all participants for feedback, and respondents agreed that codes and themes represented their perceptions.

\section{Results}

The study found numerous themes related to benefits and barriers to involvement in a TD training program among faculty advisors and doctoral students, as shown in Tables 1 and 2 and elaborated upon below in each section. First we report on themes of actual experiences in the program after five years (vs. baseline anticipated benefits and barriers). Second, we compare perceptions at baseline and at five-years in order to gain a longitudinal perspective on anticipated vs. actual benefits and barriers.

\section{Faculty benefits and barriers}

Benefits. At five years, five themes emerged regarding faculty opinions of benefits of participating in a TD training program: (a) broadens thinking, (b) builds networking and collaborations, (c) increases opportunities, (d) increases guidance and support, and (e) enriches faculty scholarship by way of TD students (Table 1). The first four themes were mentioned by all three faculty groups 
Table 1 Benefit themes mentioned by two or more faculty or two or more student focus groups at baseline and after five years ${ }^{a}$

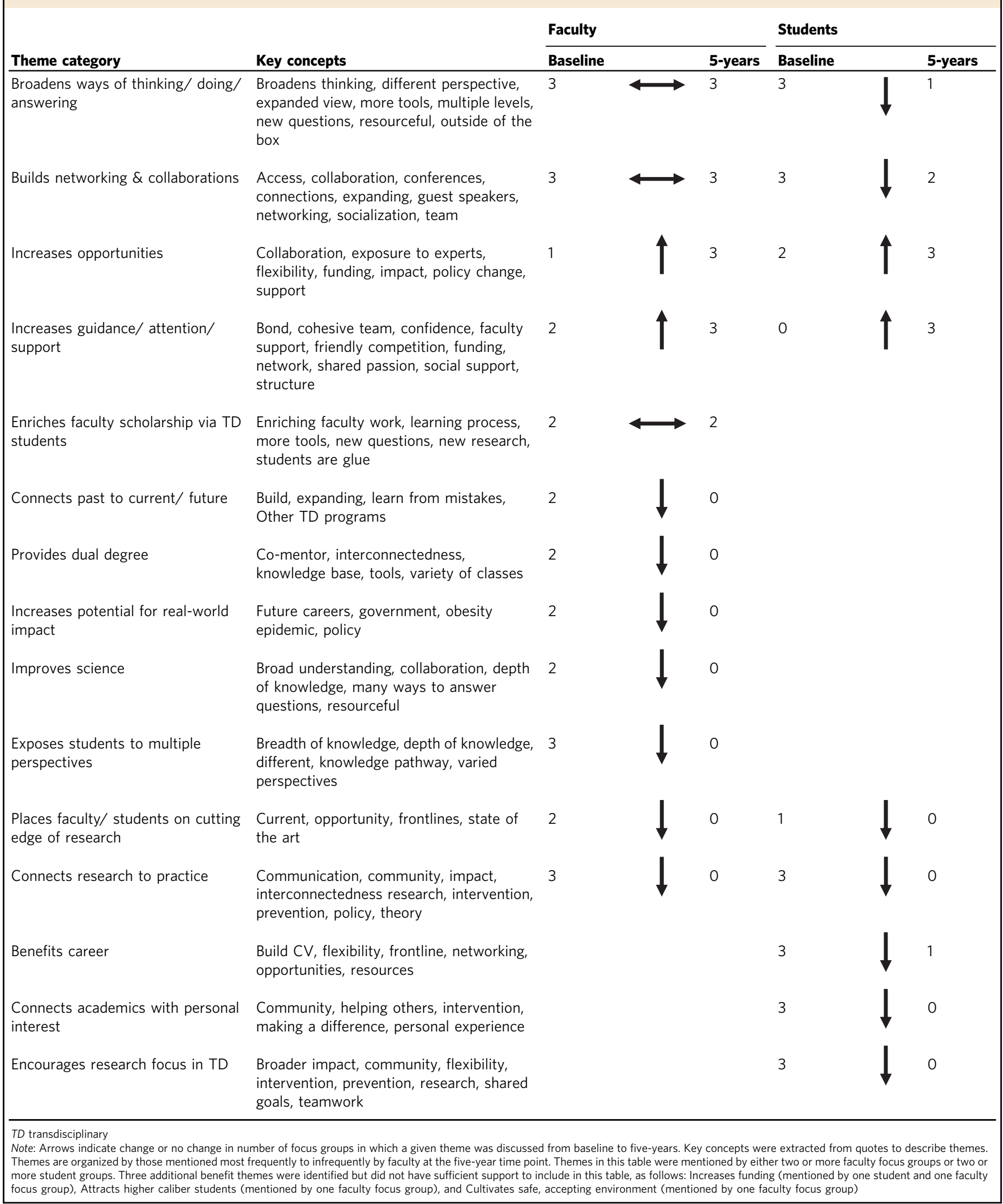


Table 2 Barrier themes mentioned by two or more faculty or two or more student focus groups at baseline and after five years ${ }^{a}$

\begin{tabular}{|c|c|c|c|c|c|}
\hline \multirow[b]{2}{*}{ Theme category } & \multirow[b]{2}{*}{ Key concepts } & \multicolumn{2}{|l|}{ Faculty } & \multicolumn{2}{|l|}{ Students } \\
\hline & & Baseline & 5-years & Baseline & 5-years \\
\hline $\begin{array}{l}\text { Creates concerns for faculty } \\
\text { advancement }\end{array}$ & $\begin{array}{l}\text { Advancement, documenting scholarly productivity, } \\
\text { evaluation, incentives, inconsistent expectations, } \\
\text { overwhelming for junior faculty, time, value }\end{array}$ & 2 & 2 & & \\
\hline $\begin{array}{l}\text { Complicates balancing depth/ } \\
\text { breadth }\end{array}$ & $\begin{array}{l}\text { Balance, career opportunity, depth, breadth, focus, identity, } \\
\text { impact, imposture syndrome, relevance }\end{array}$ & 2 & 2 & 2 & 1 \\
\hline $\begin{array}{l}\text { Creates student time } \\
\text { concerns/ places too much on } \\
\text { plate }\end{array}$ & $\begin{array}{l}\text { Comparison, expectations, logistics, longitudinal research } \\
\text { limitations, overwhelming, pressure, relevance of } \\
\text { coursework, sleep, timeline }\end{array}$ & 0 & 2 & 2 & 3 \\
\hline Complicates logistics & $\begin{array}{l}\text { Administration barriers, asking questions, communication, } \\
\text { defining research focus, department differences, inventing } \\
\text { the wheel, publishing, requirements, scheduling, } \\
\text { sustainability, time, value }\end{array}$ & 3 & 2 & 3 & 1 \\
\hline $\begin{array}{l}\text { Causes internal conflicts for } \\
\text { faculty }\end{array}$ & $\begin{array}{l}\text { External criticism, guilt, insecurities, overwhelmed, personal } \\
\text { barriers }\end{array}$ & 2 & 1 & & \\
\hline $\begin{array}{l}\text { Magnifies faculty time/ } \\
\text { pressure concerns }\end{array}$ & $\begin{array}{l}\text { Colleague pressure, commitment, difficult, overwhelmed, } \\
\text { time management, time sink, two fulltime jobs }\end{array}$ & 2 & 1 & & \\
\hline Creates mentoring concerns & Effective guidance, rogue qualities, student independence & 3 & 1 & & \\
\hline $\begin{array}{l}\text { Requires immediate sacrifice } \\
\text { for uncertain future gain }\end{array}$ & Hard to balance, large commitment, time, unclear benefits & 3 & 0 & & \\
\hline $\begin{array}{l}\text { Spawns disciplinary } \\
\text { disagreements / boundary } \\
\text { disputes }\end{array}$ & $\begin{array}{l}\text { Artificial boundaries, departmental differences, different } \\
\text { points of view, disadvantage, disagreements, ego, grounding } \\
\text { in one discipline, jargon, silos }\end{array}$ & 2 & 0 & 3 & 0 \\
\hline $\begin{array}{l}\text { Generates negative perception } \\
\text { of TD }\end{array}$ & $\begin{array}{l}\text { Challenge to think outside of the box, complex, criticism, } \\
\text { design challenges, expertise, isolation, logistics of } \\
\text { publishing, method challenges, no precedent, requires true } \\
\text { integration, silos }\end{array}$ & 1 & 0 & 3 & 0 \\
\hline $\begin{array}{l}\text { Makes providing clear and } \\
\text { collective expectations } \\
\text { difficult }\end{array}$ & $\begin{array}{l}\text { Biases, culture, departmental differences, differences in } \\
\text { advisors, high expectations, inventing the wheel, } \\
\text { miscommunication, personal expectations }\end{array}$ & & & 2 & 3 \\
\hline Limits research to practice & $\begin{array}{l}\text { Individual biases, intervention limitations, lack of control, } \\
\text { public }\end{array}$ & & & 2 & 0 \\
\hline $\begin{array}{l}\text { Magnifies challenges of } \\
\text { working with multiple } \\
\text { departments }\end{array}$ & $\begin{array}{l}\text { Balance, communication challenges, departmental } \\
\text { inconsistencies, isolated from home department, jargon, } \\
\text { knowledge of other departments, red tape, time }\end{array}$ & & & 3 & 1 \\
\hline $\begin{array}{l}\text { TD transdisciplinary } \\
\text { Note: Arrows indicate change or no chang } \\
\text { Themes are organized by those mentioned } \\
\text { more student groups. Six additional barrie } \\
\text { focus group and one faculty focus group), } \\
\text { motivation concerns, and Magnifies teach }\end{array}$ & $\begin{array}{l}\text { number of focus groups in which a given theme was discussed from baseline } \\
\text { ost frequently to infrequently by faculty at the five-year time point. Themes in th } \\
\text { emes were identified but did not have sufficient support to include in this table, } \\
\text { sults in a lack of identity (mentioned by one student group), Generates universit } \\
\text { / course concerns (mentioned by one faculty focus group) }\end{array}$ & $\begin{array}{l}\text { ollows: Gly } \\
\text { el concerr }\end{array}$ & student in & pendence, & $\begin{array}{l}\text { be themes. } \\
\text { s or two or } \\
\text { ne student } \\
\text { student fit/ }\end{array}$ \\
\hline
\end{tabular}

and the last theme by two groups. Broadened thinking during the past five years stemmed from the TD lecture series, stimulating intellectual exchange across fields, and the need for students to stretch themselves cognitively to succeed in required TD courses. Examples of networking included students having multidisciplinary advisors and opportunities for peer collaboration among students and among faculty TD mentors. All faculty groups noted increased opportunities for TD students such as access to obtain seed grant funding to propose and conduct research projects with TD peers, and opportunities to collaborate with researchers in other disciplines. One faculty member said, "It's something about the structure of being in a TD program that emboldens them and I think makes professors more receptive than say just a random social work student wanting to connect with a rat [rodent] researcher...because they're in this program, it validates that desire to reach out across disciplines." Faculty noted the increased guidance, attention, and support for TD students through team-building events, multiple faculty mentors, and a formal annual review. "The students really put effort into tracking their products... We put effort into helping them establish goals 
and targets. It's just different... it's very high quality annual review, and with a multi-disciplinary faculty."

Finally, two faculty groups talked about how TD students enrich faculty scholarship. One faculty member described students as "the glue that helps it [TD collaborations] work." Faculty noted that TD students altered their own research trajectory: “...I think in the course of this project, I actually started to go into another direction in terms of research. I think one of the reasons that I was able to was because... it was easy for me to listen to the other people, and to figure out, "How do I look at this new area? How can I integrate that with what I am currently doing?"

Barriers. As shown in Table 2, three barriers persisted from baseline and one new barrier was identified at five years. Persistent themes included concerns about career advancement, balancing depth and breadth of research, and logistics. The new barrier noted was that students may have "too much on their plates" regarding time spent on additional coursework and how far they could push students to excel in multiple degree programs and domains. At both time points faculty reported more challenges for junior faculty than senior faculty regarding career advancement, tenure, unclear standards to evaluate TD work, and time investment given tenure expectations. Faculty noted that the university supports interdisciplinary work but that independent research capability was still the single most important quality valued by departments. They also discussed that for senior faculty, diversifying interests is viewed as a desirable goal at the university and department levels, but the same is not true for pretenured faculty.

\section{Student benefits and barriers}

Benefits. At five years, three prominent themes emerged regarding the benefits to students of participating in a TD program: (a) broader networking and collaborations, (b) greater learning opportunities, and (c) increased guidance, attention, and support from faculty and other students (Table 1). Two cohorts discussed the opportunity to network and collaborate with faculty and students in other departments and institutions. Greater learning opportunities mentioned included: exposure to experts, getting to take classes not available to traditional students, and funding to attend conferences. Finally, all three cohorts discussed increased guidance, attention, and support as a benefit from the TD program and having multiple advisors.

Barriers. At five years, two themes emerged regarding barriers of participating in a TD program for students: (a) time concerns and (b) unclear expectations (Table 2). Students had concerns about having too much to do and never enough time, and felt they were behind or under greater pressure compared to traditional $\mathrm{PhD}$ students mentored by the same advisors. Students voiced frustration about advisors' implicit expectations that they be at the same place in their research as traditional $\mathrm{PhD}$ students, despite the additional classes required for the MPH and TD training; though they noted that expectations varied by discipline and advisor. Some advisors expected their students to focus on the $\mathrm{MPH}$ the first two years, while others expected them to advance their doctoral research and earn an MPH simultaneously.

Longitudinal findings. Overall, more benefits and barriers were reported by faculty at baseline than at five years. Seven of the 12 benefit themes (Table 1) and five of the 10 barrier themes (Table 2) did not persist as themes at five years. Students also reported more benefits and barriers at baseline than at five years. Five of the eight benefit themes (Table 1) and six of the eight student barrier themes (Table 2) did not persist as themes at five years.

Meta-themes. Finally, we examined the data and themes for potential meta-themes to illustrate the core findings in a more parsimonious way. This process condensed the 28 themes that were mentioned in two or more of the faculty/student focus groups at baseline and five years into six overarching themes (see Fig. 1). For benefits, three meta-themes emerged: (a) improves scholarship, (b) increases individual benefits, and (c) expands research impact. For barriers, three meta-themes emerged: (a) increases workload, (b) heightens potential for conflict, and (c) generates unique concerns about faculty promotion.

\section{Discussion}

This exploratory study sought to uncover the benefits and barriers of participating in a TD training program over time. Discussion of findings on benefits (Table 1) and barriers (Table 2) are organized by themes and are discussed below in comparison to baseline perceptions and current literature. We highlight overall program level recommendations based on meta-themes that emerged from each group of informants (Fig. 1). Finally, themes that persisted or emerged at five years are displayed in Fig. 2 in order to visualize convergent and divergent themes among faculty and students.

\section{Faculty benefits and barriers}

Broad range of benefits: potential retention incentives. Prior research has demonstrated gains in researcher productivity from working in TD teams (Hall et al., 2012), but this study identified a much wider range of benefits to individual faculty and potentially to the university over time (Table 1). For example, in academia, retaining talented faculty is a growing challenge. A 2013 survey of tenure track faculty $(n=784)$ at a major U.S. public research university found that more than a quarter reported intentions to leave the university within the next two years (O'Meara et al., 2013). Although greater salary was the main reason, faculty also reported the desire for greater collegiality in their unit (11\%) and better work-life balance (12\%) as reasons for leaving. Thus, the benefits reported in this study may help with faculty retention. In addition to increased productivity (Hall et al., 2012), TD collaborations enhance the potential for innovative scholarship, more collaborations, TD lectures, and greater faculty satisfaction, all of which may contribute to retention. These factors should be of interest to administration and may serve as motivation to initiate and incentivize TD collaborations university-wide.

Perceptions are not always actualized. A surprising finding was that a fewer number of benefits and barriers were identified by faculty at five years than at baseline; however it is unclear if this suggests that anticipated benefits and barriers did not materialize, or simply were not discussed at five years. For instance, students earn two degrees in five years, a clear benefit identified at baseline but not discussed at five years. Another example of a benefit that was anticipated but not reported at five years was the program's capacity to train students to conduct high impact, policy-relevant research. At five years, faculty indicated a more realistic goal was for students to build TD research skills as a foundation for an impactful TD career. Finally, faculty concerns about mentoring that were anticipated at baseline were reduced at five years. Concerns for faculty advancement still persisted at five years, which is similar to what Armstrong and Jackson-Smith (2013) found when they interviewed scientists working in interdisciplinary teams. What does this tell us? First, it may be that anticipated barriers can be successfully resolved over time; and 


\section{Benefits}

Meta-themes

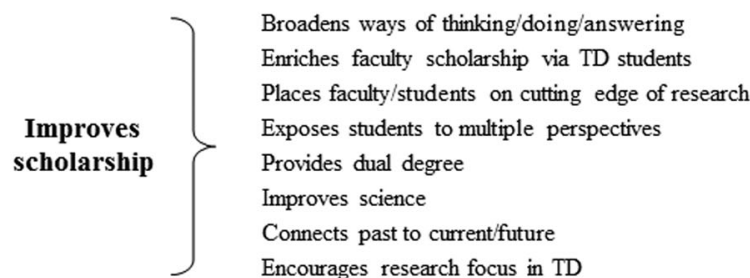

$\left.\begin{array}{c}\text { Increases } \\ \text { individual } \\ \text { benefits }\end{array}\right\} \begin{aligned} & \text { Builds networking and collaborations } \\ & \text { Benefits career } \\ & \text { Connects academics with personal interest } \\ & \text { Increases opportunities } \\ & \text { Increases guidance/attention/support }\end{aligned}$

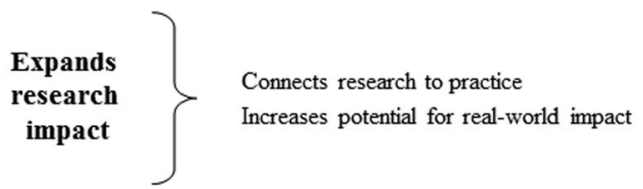

\section{Barriers}

Meta-themes Themes
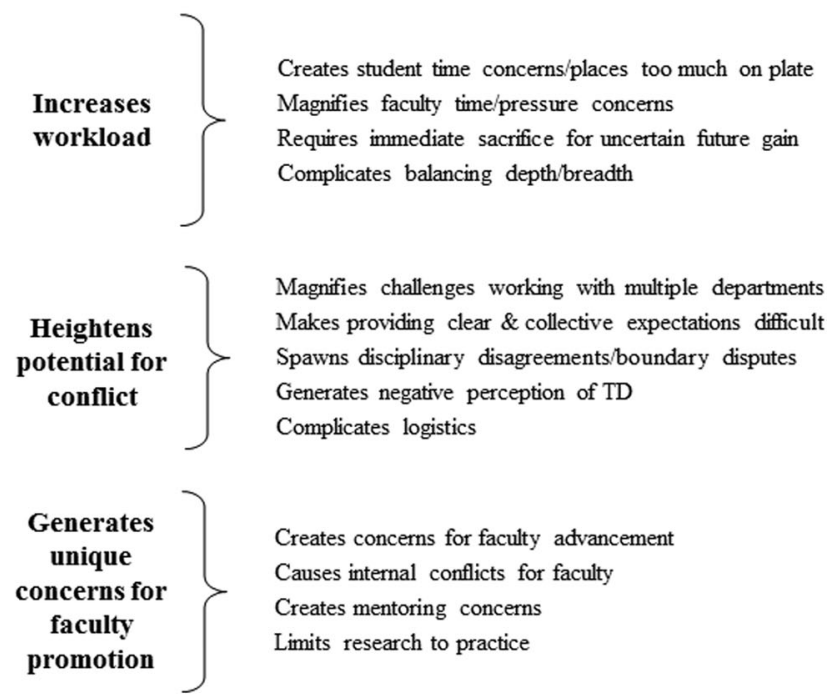

Fig. 1 Meta-themes derived from themes related to benefit and barriers to transdisciplinary (TD) graduate training. Six overarching themes emerged from the original 28 themes that were mentioned in two or more of the faculty/ student focus groups at baseline and at five years

Faculty
Students
Faculty \& Students

\section{fis}
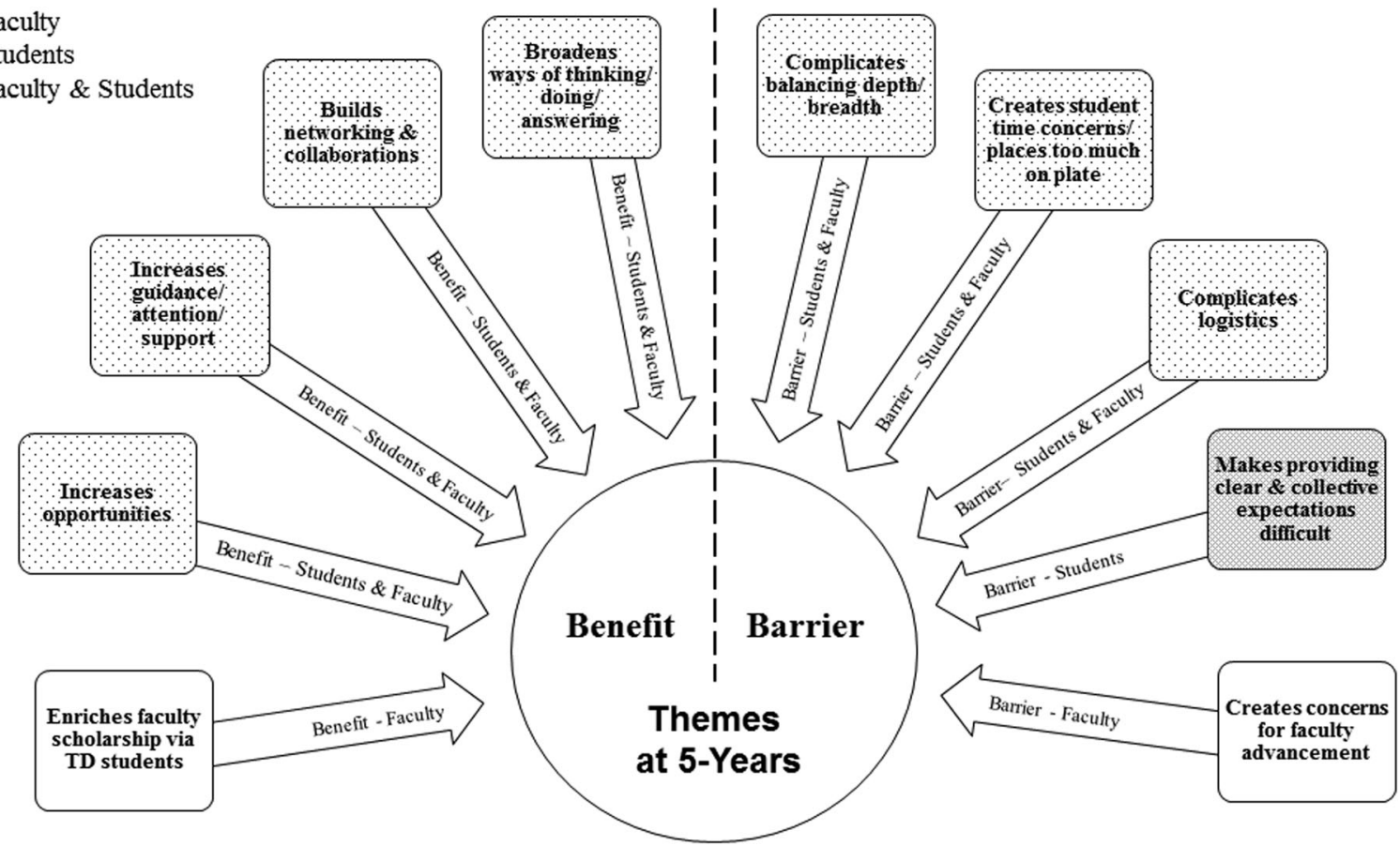

Fig. 2 Themes related to benefits and barriers to transdisciplinary (TD) graduate training at five years. Benefits and barriers discussed by only faculty at five years are shown on white background; benefits and barriers discussed by only students at five years are shown on crosshatched background; and benefits and barriers discussed by both faculty and student groups at five years are shown on dotted background

secondly, enumerating anticipated concerns at the start of a TD program may alert the team to address them pro-actively. Thus, we encourage TD planners and stakeholders to openly discuss but not be thwarted by anticipated problems.

\section{Student benefits and barriers}

$T D$ and traditional students report similar experiences. Many of the well-documented challenges experienced by traditional students overlap with those identified in this study among TD students. For example, traditional students have concerns about being inadequately informed about the doctoral training process, unclear expectations of advisors, and time to degree completion (Barnes and Randall, 2012; Liechty et al., 2009). In the current study, TD students also talked about their frustrations with unclear expectations from their multiple advisors and departments. Participating in TD training was a new experience for most involved, and expectations of each disciplinary doctoral 
program differed, so the challenge of providing clear and collective expectations to students was not surprising. Other sources of stress noted in the literature among traditional students included lack of personal time and meeting program deadlines and requirements (Kurtz-Costed et al., 2006; Graybill et al., 2006). Similarly, all three TD cohorts also discussed concerns about having enough time to complete course work, making progress on their research, and having a personal life. Again, given the increased demands of a TD and dual degree program, time management is an expected challenge. However, despite students' stress about time pressure, all students in this study have graduated on time or are on track to graduate with two degrees in less than six years. We speculate that the additional program support and accountability of a focused TD program enables TD students to achieve timely degree completion.

Weaknesses of traditional programs may be strengths of TD programs. Traditional doctoral students have reported dissatisfaction with quality of mentoring and support from faculty and disappointment in the direction provided by their mentors (Nyquist and Woodford, 2000). In contrast, TD students in all three cohorts described ample attention and support from their faculty mentors and were aware that their non-TD peers may not always enjoy this benefit. Even if TD students received equivalent attention from one advisor as a traditional student, the fact that TD students have two or more advisors means they likely have more contact with faculty. Therefore, students in TD programs structured as described here are likely to experience increased attention and support (a benefit also reported among students in a doctoral interdisciplinary program, Bosque-Pérez et al., 2016). A second example is that traditional students reported frustration at the narrowness of required courses and lack of access to courses in other disciplines (Golde and Dore, 2001). One study even concluded that, "students enrolled in research intensive universities may not be getting the opportunities to publish, attend professional conferences, develop professional networks or gain teaching experience" (Barnes and Randall, 2012, p 69). In contrast, TD students in all three cohorts described having access to a wide variety of courses, the opportunity to present at professional conferences in multiple fields, and greater exposure to experts, all of which provided them ample opportunities to network and collaborate with researchers in other institutions and disciplines. These benefits are consistent with a TD mission and therefore not surprising; however programmatic support, cooperation among relevant departments, availability of funding, and leadership of the TD program will likely affect the degree to which these benefits can be realized by students in other TD programs.

\section{Comparing faculty and student experiences}

Faculty and students as co-learners. A prior study reported on benefits and barriers from the perspective of TD trainees (e.g., junior faculty, post-doctoral, and doctoral students) (Vogel et al., 2012). An important contribution of the current study is to prospectively evaluate a program from multiple vantage points. This allows for comparison between stakeholders in order to understand where experiences overlap or differ. The majority of benefit and barrier themes were discussed by both faculty and students at five years (see Fig. 2). Both groups talked about four benefits of being part of a TD team: broadened thinking, building new collaborations, and greater student support and opportunities. In addition, faculty talked about an additional benefitthat their own scholarship had been enriched from mentoring a TD student. Several of the barriers were also noted by both faculty and students, including balancing depth and breadth, time management and workload, and challenging logistics.
To our knowledge, this is the first study that has looked longitudinally at both faculty and student experiences together. The convergence in reported experiences suggests the program is generating similar benefits and barriers recognized by both faculty and students. Similarity of benefits may reflect the increased mentoring built into this program, which may have catalyzed a shared sense of broadened thinking and scholarly enrichment. Findings suggest that this mutual engagement with TD fostered a sense of collaborative discovery by faculty and students, thus enhancing students' experience of support. This type of co-learning is of interest because perceived faculty support is related to student program satisfaction, as well as student life satisfaction (Tompkins et al., 2016). While the TD students perceived a high level of support from faculty, students in traditional programs perceived lower levels of socioemotional support from faculty than from family, friends, and student-peers (Tompkins et al., 2016). Graduate school is a notoriously stressful endeavor and high stress can interfere with academic performance and degree completion (Lovitts, 2001). Therefore, despite TD students reporting a heavy workload, having greater shared experiences with faculty and opportunities for co-learning may mitigate student stressors. This is another potential important benefit of TD education of interest to those initiating or building TD programs at their institutions.

Meta-themes. The meta-themes identified six overarching themes: three benefits and three barriers (see Fig. 1) across students and faculty at both time points. The benefit meta-themes (improves scholarship, increases individual benefits, and expands research impact) highlight what participants of a successful TD program would hope to gain by their involvement and are consistent with the mission of TD education. The barrier metathemes (increases workload, heightens potential for conflict, and generates concerns about faculty promotion) identify challenges for those involved with TD education. However, they also offer a platform for growth and improvement.

For instance, greater workload does not have to be viewed through a purely negative lens; under the right conditions, greater workload can inspire greater efficiency and productivity. Conflict also holds positive potential; when engaged constructively, conflict spurs growth (De Dreu, 2006). For example, the departmental and disciplinary boundary disputes noted at baseline were not mentioned by any focus group at five years; further, students and faculty alike noted the value of collaboration, networks, and support across and between disciplines and programs at five years. Regarding faculty promotion concerns, these may lessen as we approach a paradigm shift in the structure of academia and doctoral training, as TD science and collaboration become the new norm (Bennett et al., 2010; Chastin et al., 2016; Hirsch et al., 2008; Rimer and Abrams, 2012; Stokols et al., 2008b). Existing TD training programs must continue to gather and evaluate data in order to build evidence-based approaches to TD training and pedagogy and to spur innovation at the institutional level in order to support team science that can solve complex global problems.

Limitations. There are several limitations that should be considered. First, because open-ended focus groups were used, we cannot be certain that themes were absent simply because they were not reported. This was a limitation we accepted because it was an exploratory study and our goal was to gather the widest range of possible themes. Hopefully our results will contribute to the future development of standardized measures. Second, this was a problem-focused TD training program with a small sample size, and thus may have limited generalizability. Third, due to the 
funding parameters of the training program (3-5 students each year for 3 years), sequential cohorts were enrolled in the study over three years, rather than enrolling all students at one time point. Thus, by the third cohort, the program was more refined and the team had resolved some of the logistical and scheduling barriers noted in year one, but the core structure of the program remained unchanged. Finally, five years is a relatively short time, and only a third of the students have now completed their training. However, this study may be the first truly prospective evaluation of a TD doctoral program and we plan to follow students and faculty over 10 years.

\section{Conclusion}

The findings of this study provide important implications for others considering involvement in TD training programs. It will be important for TD team leaders and their institutions to attend to faculty concerns about the barriers to participation in $\mathrm{TD}$ research and education, particularly concerns about advancement, the perceptions of TD by colleagues, and the degree of commitment required by participants. Leaders can use examples of existing higher education TD programs as roadmaps for developing TD teams and training programs and encouragement to persist despite anticipated barriers. As complex health and global problems continue to be exposed, the unleashed potential of TD team science and the importance of carefully designed TD doctoral programs are increasingly apparent. Continued efforts to build an evidence base to understand the effectiveness and impact of various components of TD education are needed.

Received: 31 July 2017 Accepted: 17 October 2017

Published online: 28 November 2017

\section{References}

Abrams DB (2006) Applying transdisciplinary research strategies to understanding and eliminating health disparities. Health Educ Behav 33(4):515-531. https:// doi.org/10.1177/1090198106287732

Armstrong A, Jackson-Smith D (2013) Forms and levels of integration: evaluation of an interdisciplinary team-building project. J Res Pract 9(1), Article M1. http://jrp.icaap.org/index.php/jrp/article/view/335/297

Barnes BJ, Randall J (2012) Doctoral student satisfaction: an examination of disciplinary, enrollment, and institutional differences. Res High Educ 53 (1):47-75. https://doi.org/10.1007/s11162-011-9225-4

Bennett LM, Gadlin H, Levine-Finley S (2010) Collaboration and team science: a field guide: NIH Office of the Ombudsman, Center for Cooperative Resolution. https://ccrod.cancer.gov/confluence/download/attachments/47284665/ teamscience_fieldguide.pdf. Accessed 3 July 2017

Bernstein JH (2015) Transdisciplinarity: a review of its origins, development, and current issues. J Res Prac 11(1), Article R1. http://jrp.icaap.org/index.php/jrp/ article/view/510/412

Bosque-Pérez NA, Klos PZ, Force JE, Waits LP, Cleary K, Rhoades P, Finegan B (2016) A pedagogical model for team-based, problem-focused interdisciplinary doctoral education. BioScience 66(6):477-488. https://doi.org/ 10.1093/biosci/biw042

Braun V, Clarke V (2006) Using thematic analysis in psychology. Qual Res Psychol 3(2):77-101. https://doi.org/10.1191/1478088706qp063oa

Carey MA (1994) Forms of interviewing. Qual Health Res 5(4):413-416

Chastin SFM, De Craemer M, Lien N, Bernaards C, Buck C, Oppert J-M et al. (2016) The SOS-framework (Systems of Sedentary behaviours): an international transdisciplinary consensus framework for the study of determinants, research priorities and policy on sedentary behaviour across the life course: a DEDIPAC-study. Int J Behav Nutr Phys Act 13:83. https://doi.org/10.1186/ s12966-016-0409-3

Cooper LA, Boulware LE, Miller III ER, Hill Golden S, Carson KA, Noronha G, Bone LR (2013) Creating a transdisciplinary research center to reduce cardiovascular health disparities in Baltimore, Maryland: lessons learned. Am J Public Health 103(11):e26-e38. https://doi.org/10.2105/AJPH.2013.301297

Dedoose Version 7.0.23 (2016) Web application for managing, analyzing, and presenting qualitative and mixed method research data. SocioCultural Research Consultants, LLC, Los Angeles, CA. www.dedoose.com
De Dreu CKW (2006) When too little or too much hurts: evidence for a curvilinear relationship between task conflict and innovation in teams. J Manag 32 (1):83-107. https://doi.org/10.1177/0149206305277795

Golde CM, Dore TM (2001) At cross purposes: what the experiences of doctoral students reveal about doctoral education. Philadelphia, PA: a report prepared for The Pew Charitable Trusts. http://www.phdcompletion.org/promising/ golde.pdf. Accessed 23 July 2017

Graybill JK, Dooling S, Shandas V, Withey J, Greve A, Simon GL (2006) Rough guide to interdisciplinarity: graduate student perspectives. BioScience 56 (9):757-763. https://doi.org/10.1641/0006-3568(2006)56[757:ARGTIG]2.0. $\mathrm{CO} ; 2$

Hall KL, Stokols D, Moser RP, Taylor BK, Thornquist MD, Nebeling LC et al. (2008) The collaboration readiness of transdisciplinary research teams and centers findings from the National Cancer Institute's TREC Year-One evaluation study. Am J Prev Med 35(2 Suppl):S161-S172. https://doi.org/ 10.1016/j.amepre.2008.03.035

Hall KL, Stokols D, Stipelman BA, Vogel AL, Feng A, Masimore B et al. (2012) Assessing the value of team science: a study comparing center-and investigator-initiated grants. Am J Prev Med 42(2):157-163. https://doi.org/10.1016/ j.amepre.2011.10.011

Harrison K, Bost KK, McBride BA, Donovan SM, Grigsby-Toussaint DS, Kim J et al. (2011) Toward a developmental conceptualization of contributors to overweight and obesity in childhood: the six-Cs model. Child Dev Perspect 5 (1):50-58. https://doi.org/10.1111/j.1750-8606.2010.00150.x

Hesse-Biber SN, Leavy PL (2011) Focus group interviews. In: Hesse-Biber SN, Leavy P (eds) The practice of qualitative research. Sage, Thousand Oaks, p 163-192

Hirsch H, Hoffmann-Riem GH, Biber-Klemm S, Grossenbacher-Mansuy W, Joye D, Pohl C et al. (2008) Handbook of transdisciplinary research. Springer, Dordrecht

Jacob JW (2015) Interdisciplinary trends in higher education. Pal Comms, 1 (15001) http://dx.doi.org/10.1057/palcomms.2015.1

Krueger RA, Casey MA (2001) Designing and conducting focus group interviews In Social development papers: Social analysis, selected tools and techniques: Social Development Family of The World Bank. http://siteresources. worldbank.org/INTCDD/Resources/SAtools.pdf. Accessed 20 June 2017

Kurtz-Costed B, Helmke LA, Ülkü-Steiner B (2006) Gender and doctoral studies: the perceptions of Ph.D. students in an American university. Gend Educ 18 (2):137-155. https://doi.org/10.1080/09540250500380513

Liechty JM, Liao M, Pegorraro Schull C (2009) Facilitating dissertation completion and success among doctoral students in social work. J Soc Work Educ 45 (3):481-497. https://doi.org/10.5175/JSWE.2009.200800091

Lincoln YS, Guba EG (1985) Establishing trustworthiness. In: Lincoln YS, Guba EG (eds) Naturalistic inquiry. Sage, London, p 289-331

Lovitts BE (2001) Leaving the ivory tower: the causes and consequences of departure from doctoral study. Rowman and Littlefield, Lanham, MD

McDaniels M, Skogsberg E (2017) The scholars we need: preparing transdisciplinary professionals by leveraging the scholarship of practice. New Directions for Higher Education (178), 71-83. https://doi.org/10.1002/he.20235

Morgan DL (1996) Focus groups as qualitative research. Vol. 16. Sage publications. Morgan DL, Krueger RA (1993) When to use focus groups and why. In: David L. Morgan (ed) Successful focus groups: advancing the state of the art. SAGE Publications, Inc, Thousand Oaks, CA, p 3-19

Namey E, Guest G, Thairu L, Johnson L (2008) Data reduction techniques for large qualitative data sets. In: Guest G, MacQueen KM (eds) Handbook for teambased qualitative research. Altamira, United Kingdom, p $137-161$

Nash JM (2008) Transdisciplinary training: key components and prerequisites for success. Am J Prev Med 35(2 Suppl):S133-S140. https://doi.org/10.1016/j. amepre.2008.05.004

National Research Council (NRC) (2014) Convergence: Facilitating transdisciplinary integration of life sciences, physical sciences, engineering, and beyond. The National Academies Press, Washington, DC. http://www8.nationalacademies. org/onpinews/newsitem.aspx?RecordID $=18722$. Accessed 15 July 2017

Neuhauser L, Pohl C (2015) Integrating transdisciplinary and translational concepts and methods into graduate education. In: Gibbs P (ed) Transdisciplinary professional learning and practice. Springer International Publishing, Switzerland, p 99-120

Neuhauser L, Richardson D, Mackenzie S, Minkler M (2007) Advancing transdisciplinary and translational research practice: issues and models of doctoral education in public health. J Res Pract 3(2), Article M19. http://jrp.icaap.org/ index.php/jrp/article/view/103/97

Nishtar S, Gluckman P, Armstrong T (2016) Ending childhood obesity: a time for action. The Lancet 387(10021):825-827. https://doi.org/10.1016/S0140-6736 (16)00140-9

Nyquist JD, Woodford BJ (2000) Re-envisioning the Ph.D: what concerns do we have? Vol. 1. University of Washington, Seattle. https://depts.washington. edu/envision/resources/ConcernsBrief.pdf. Accessed 10 July 2017 
O’Meara K, Garvey J, Niehaus E, Corrigan K (2013) The work environment for tenure-track/tenured faculty at the university of maryland: results from the 2013 UMD work environment survey. College Park, MD: Univ. of Maryland ADVANCE Program. https://advance.umd.edu/sites/advance.umd.edu/files/ Campus\%20Service\%20Inequality\%20A\%20study\%20of\%20UMCP\% 20Faculty\%20Activity\%20Report\%20Data.pdf. Accessed 20 July 2017

Rimer BK, Abrams DB (2012) Present and future horizons for transdisciplinary research. Am J Prev Med 42(2):200-201. https://doi.org/10.1016/j. amepre.2011.10.010

Ryan GW, Bernard HR (2003) Techniques to identify themes. Field Methods 15 (1):85-109. https://doi.org/10.1177/1525822X02239569

Shandas V, Brown SE (2016) An empirical assessment of interdisciplinarity: perspectives from graduate students and program administrators. Innovative High Educ 41:411-423. https://doi.org/10.1007/s10755-016-9362-y

Stokols D, Hall KL, Vogel AL (2013) Transdisciplinary public health: definitions, core characteristics, and strategies for success. In: Haire-Joshu D, McBride TD (eds) Transdisciplinary public health: research, methods, and practice. Jossey-Bass, San Francisco, p 3-30

Stokols D (2006) Toward a science of transdisciplinary action research. Am J Commun Psychol 38(1-2):63-77. https://doi.org/10.1007/s10464-006-9060-5

Stokols D, Misra S, Moser RP, Hall KL, Taylor BK (2008a) The ecology of team science: understanding contextual influences on transdisciplinary collaboration. Am J Prev Med 35(2 Suppl):S96-S115. https://doi.org/10.1016/j. amepre.2008.05.003

Stokols D, Hall KL, Taylor BK, Moser RP (2008b) The science of team science: overview of the field and introduction to the supplement. Am J Prev Med 35 (2 Suppl):S77-S89. https://doi.org/10.1016/j.amepre.2008.05.002

Tompkins KA, Brecht K, Tucker B, Leander LL, Swift JK (2016) Who matters most? The contribution of faculty, student-peers, and outside support in predicting graduate student satisfaction. Train Educ Prof Psychol 10 (2):102-108. https://doi.org/10.1037/tep0000115

Townsend T, Pisapia J, Razzaq J (2015) Fostering interdisciplinary research in universities: a case study of leadership, alignment and support. Stud High Educ 40(4):658-675. https://doi.org/10.1080/03075079.2013.842218

Vanasupa L, McCormick KE, Stefanco CJ, Herter RJ, McDonald M (2012) Challenges in transdisciplinary, integrated projects: reflections on the case of faculty members' failure to collaborate. Innovative High Educ 37(3):171-184. https://doi.org/10.1007/s10755-011-9199-3

Vogel AL, Feng A, Oh A, Hall KL, Stipelman BA, Stokols D et al. (2012) Influence of a National Cancer Institute transdisciplinary research and training initiative on trainees' transdisciplinary research competencies and scholarly productivity. Transl Behav Med 2(4):459-468. https://doi.org/10.1007/ s13142-012-0173-0

Wall S, Shankar I (2008) Adventures in transdisciplinary learning. Stud High Educ 33(5):551-565. https://doi.org/10.1080/03075070802373008

Willetts J, Mitchell C (2016) Chapter 9: Assessing transdisciplinary doctoral research. In: Fam D, Palmer J, Riedy C, Mitchell C (eds) Transdisciplinary research and practice for sustainability outcomes (p 122-136) Taylor \& Francis
World Health Organization (2016) World health statistics 2016: monitoring health for the SDGs, sustainable development goals. http://www.who.int/gho/ publications/world_health_statistics/2016/en/. Accessed 15 July 2017

\section{Data availability}

The datasets generated during and/or analyzed during the current study are not publicly available due to the fact that they contain personal identifiers; but they are available from the corresponding author on reasonable request with additional IRB approvals prior to sharing.

\section{Acknowledgements}

This work was supported by the Agriculture and Food Research Initiative of the U.S Department of Agriculture National Institute of Food and Agriculture under the under the Illinois Transdisciplinary Obesity Prevention Program (I-TOPP) grant (2011-6700130101) to the Division of Nutritional Sciences at the University of Illinois at UrbanaChampaign. The authors would like to thank members of the I-TOPP Evaluation and Assessment Committee, and students and faculty for their participation in this ongoing evaluation. A conference abstract based on preliminary findings of this study was published by Donovan et al. (2013) in the Journal of Nutrition Education and Behavior, 45, S80. DOI:10.1016/j.jneb.2013.04.212.

\section{Additional information}

Competing interests: The authors declare no competing financial interests.

Reprints and permission information is available online at http://www.nature.com/ reprints

Publisher's note: Springer Nature remains neutral with regard to jurisdictional claims in published maps and institutional affiliations.

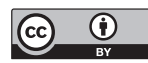

Open Access This article is licensed under a Creative Commons Attribution 4.0 International License, which permits use, sharing, adaptation, distribution and reproduction in any medium or format, as long as you give appropriate credit to the original author(s) and the source, provide a link to the Creative Commons license, and indicate if changes were made. The images or other third party material in this article are included in the article's Creative Commons license, unless indicated otherwise in a credit line to the material. If material is not included in the article's Creative Commons license and your intended use is not permitted by statutory regulation or exceeds the permitted use, you will need to obtain permission directly from the copyright holder. To view a copy of this license, visit http://creativecommons.org/ licenses/by/4.0/.

(c) The Author(s) 2017 